\title{
Patient perspectives on the impact of Crohn's disease: results from group interviews
}

\author{
This article was published in the following Dove Press journal: \\ Patient Preference and Adherence \\ 13 July 2012 \\ Number of times this article has been viewed
}

\author{
Beth-Ann Norton' \\ Rosemarie Thomas ${ }^{2}$ \\ Kathleen G Lomax ${ }^{2}$ \\ Sharon Dudley-Brown ${ }^{3}$ \\ 'Massachusetts General Hospital, \\ Boston, MA, USA; ${ }^{2}$ Abbott \\ Laboratories, Abbott Park, IL, USA; \\ 3Johns Hopkins University, Schools \\ of Medicine and Nursing, Baltimore, \\ MD, USA
}

Aim: To understand the impact of Crohn's disease (CD) on various aspects of daily life from the perspective of patients living with CD. Awareness of the disease and biologic therapies, patient satisfaction and adherence, and physician (provider) relationships were also assessed.

Background: CD is a chronic, inflammatory, autoimmune disorder of the gastrointestinal tract that substantially impacts patients' physical and emotional well-being. For patients eligible for biologic therapy, anti-tumor necrosis factor agents represent an important addition to the available therapies for CD.

Methods: The study sample included biologic-naïve and biologic-experienced patients who had self-reported moderate to severe $\mathrm{CD}$, were under the care of a specialist, and agreed to film a video diary and participate in a focus group. Data from the videos and group interviews were collected from May to June of 2009 and summarized qualitatively by grouping similar answers and quotations.

Results: Of the 44 participants who submitted video diaries, 23 were biologic-experienced and 21 were biologic-naïve. Participants stated that CD caused fear and embarrassment, that they were reluctant to share the full impact of CD with family and providers, and that they relied on their provider for treatment decisions. Many participants accepted a new state of normalcy if their current medication helped their most bothersome symptoms without providing sustained remission. Participants receiving biologic therapy generally were more informed, more satisfied, and more likely to adhere to treatment regimens.

Conclusion: Participants' responses suggest a need for more patient education and more collaborative relationships between patients and providers (physicians) regarding treatment decisions.

Keywords: Crohn's disease, patient perspective, quality of life

\section{Introduction}

Crohn's disease (CD) is a complex, chronic inflammatory disorder that is associated with potentially debilitating physical symptoms, which in turn can have a substantial impact on patients' overall well-being and quality of life. Physical symptoms include diarrhea, abdominal pain, weight loss, and fatigue. CD typically has cycles of active flares and remission; in moderate to severe disease, complications such as abscesses, strictures, and fistulas can lead to hospitalization and surgery. Studies of the prevalence of CD in the United States estimate that $>400,000$ people are affected, and its prevalence appears to be increasing over time. ${ }^{1-3}$ Although CD is not as prevalent as some other chronic diseases, its impact on patients' lives is extensive.
Correspondence: B Norton

Massachusetts General Hospital,

I65 Cambridge St, 9th Floor,

Boston, MA 01224 USA

Fax + I 2124265099

Email beth-ann.norton@mssm.edu 
It typically takes anywhere from 1 to 5 years for a patient with $\mathrm{CD}$ to be diagnosed. ${ }^{4,5}$ The currently endorsed treatment strategies for CD recommend an approach in which patients are generally started on conventional therapy with corticosteroids and/or 5-aminosalicylates; then, immunosuppressants (eg, azathioprine, mercaptopurine, and methotrexate) are added if patients do not respond, become refractory to the other agents, or become dependent on systemic corticosteroids. Under this step-up strategy, biologic therapy with anti-tumor necrosis factor agents is typically reserved for patients with moderate to severe disease, despite treatment with conventional therapy. ${ }^{6,7}$ The safety and efficacy of top-down strategies, in which biologic therapies are used earlier in the course of the disease, are also being studied. ${ }^{8-10}$

The biologic therapies infliximab $\left(\right.$ Remicade $^{\circledR}$; Centocor Malvern, PA) and adalimumab (Humira ${ }^{\circledR}$; Abbott Laboratories, Abbott Park, IL) have been shown in pivotal clinical trials to induce and maintain clinical remission in patients with moderate to severe CD. ${ }^{11-15}$ Certolizumab pegol (Cimzia ${ }^{\circledR}$; UCB S.A., Brussels, Belgium) has been shown to reduce signs and symptoms of $\mathrm{CD}$ and maintain a clinical response. ${ }^{16,17}$ Anecdotal reasons for delayed biologic use include unfamiliarity with available treatment options and fear of biologics.

The importance of the patient-physician/provider relationship and patient involvement in treatment decisions has been increasingly recognized in inflammatory bowel disease (IBD), which includes CD and ulcerative colitis, ${ }^{18-20}$ as treatment options are becoming more complex with more individualized benefit-risk decisions. Nurses have a critical role as health care providers in the management of patients with IBD. ${ }^{21,22}$ A better understanding of patients' awareness of the disease and available treatment options, the overall impact on daily life, and patients' expectations for effective therapy should lead to better relationships between patients and their health care providers, better access to effective therapy, better treatment outcomes, and, ultimately, better quality of life for patients.

\section{The study}

\section{Aim}

The aim of the study was to gain a thorough understanding, from the perspective of participants living with $\mathrm{CD}$, of the impact that the disease had on various aspects of their daily life, of their awareness of the disease and biologic therapies, of their satisfaction and adherence to current treatments, of their relationship with their physician (hereafter referred to as provider), and of the motivators and potential barriers for biologic treatment.

\section{Design}

$\mathrm{M} / \mathrm{A} / \mathrm{R} / \mathrm{C}^{\circledR}$ Research was commissioned to design a qualitative research study based on participant video diaries, interviews, and group discussions.

\section{Participants}

Forty-eight men and women between the ages of 18 and 75 years were recruited. Participants were to have a physician's diagnosis of $\mathrm{CD}$, have self-reported moderate to severe $\mathrm{CD}$, be under the care of a specialist, and be taking medication to treat $\mathrm{CD}$. Both biologic-experienced and biologic-naïve participants were recruited. Biologic-experienced participants were those currently receiving biologic therapy for their $\mathrm{CD}$, and biologic-naïve participants were those who had never been treated with a biologic therapy for their CD. Patients who had failed or discontinued prior biologic therapy for any reason were excluded.

Participants who received adalimumab were recruited from the myHUMIRA database (http://www.myhumira.com). Participant selection was supplemented by other proprietary consumer health care databases that had recruited patients who were receiving other biologic therapies or were naïve to biologic therapy. These databases typically consisted of consumer panels of patients who had agreed to participate in market research and were prescreened on health care behavior. Use of such databases allows for recruitment of patients who have specific medical conditions with a low prevalence, such as CD.

\section{Data collection}

\section{Participant video diaries and monologues} (completed in May 2009)

Participants were provided Flip Video ${ }^{\mathrm{TM}}$ cameras (Cisco Systems, Inc, San Jose, CA) with instructions to create 30-minute video diaries that depicted a day in their life as a patient with $\mathrm{CD}$. Participants were asked to submit an accompanying monologue describing their experiences. Topic guidelines for the videos and monologues are summarized in Table 1.

\section{Focus groups (June 2009)}

Small, in-person group discussions were held at central locations in Chicago, Illinois; New York, New York; and Dallas, Texas. Twelve groups were split by prior biologic therapy usage (experienced versus naïve) and sex, with three 
Table I Topic guidelines for patient videos and monologues

\begin{tabular}{ll}
\hline Format & Topics \\
\hline Video & - How CD impacts family, relationships, work, \\
& and leisure time \\
- Limitations or frustrations experienced because & of CD or the medications for CD \\
- Activities or experiences for which participation & is not possible or is limited because of CD \\
- How CD-related medications are taken & - How long since you were diagnosed? \\
Monologue & - How does CD feel physically, mentally, \\
& and emotionally? \\
& - How has your life changed since your diagnosis? \\
& - What does it feel like to take medications daily?
\end{tabular}

Abbreviation: $C D$, Crohn's disease.

to four participants per group. Each group discussion was 2 hours long and was led by a moderator from M/A/R/C Research. Group interviews were highly exploratory in nature and structured around the topic areas described in Table 2.

\section{Ethical considerations}

Participants were required to sign the Abbott Market Research Participant form, indicating their willingness to participate in this type of market research, which was audioand video-recorded, and to share information about their condition for an honorarium.

\section{Data analysis}

The video monologues were uploaded to the $\mathrm{M} / \mathrm{A} / \mathrm{R} / \mathrm{C}$ Research server and reviewed by the moderator in preparation for the focus groups. All participants who submitted a video were invited to participate in an in-person focus group.

Table 2 Focus-group discussion topics

\begin{tabular}{ll}
\hline Theme & Topics \\
\hline Living with CD & - What it feels like physically and emotionally \\
& to have CD \\
- The impact CD has on patients' lives from & personal, professional, and social points of view \\
Experience with & - Past and current treatment history, including \\
CD treatments & relationship with and influence of healthcare \\
& - Provider \\
& - The ideal CD treatment \\
& Perceptions of the degree of satisfaction with \\
Awareness and & - General disease awareness \\
usage of biologics & - Awareness of and experience with adalimumab \\
& and other biologics \\
& - Triggers for use or non-use of a biologic agent \\
& Factors affecting compliance and discontinuation
\end{tabular}

Abbreviation: CD, Crohn's disease.
Data from the videos and group interviews were summarized qualitatively by grouping similar answers and quotations. Descriptive demographic data were also collected.

\section{Results \\ Participant characteristics}

Forty-eight men and women between the ages of 18 and 75 years were recruited. Forty-four participated in the video diary phase of the research and 43 in the focus groups. In the video diary phase of the research, the mean age was 40 years, and $50 \%$ of the participants were women. One man participated in the video diary phase but did not attend a focus group.

Twelve focus groups were conducted, with three to four participants composing each group. Six focus groups included participants who were not receiving biologic therapy: three for men and three for women. Three focus groups were conducted with participants receiving adalimumab: two for men and one for women. There were three focus groups for participants receiving a biologic therapy other than adalimumab: one for men and two for women.

The biologic cohort had varying lengths of time on biologic therapy, ranging from $<3$ months to $>6$ months. More than half of the participants reported receiving biologic therapy for $>6$ months and always being adherent to treatment regimens. All participants stated that CD had at least some impact on their life. Other participant characteristics are presented in Table 3.

The two groups in this study were fairly similar in education level, disease severity, and disease duration. Both groups had twelve participants with college degrees, with a higher number of participants in the biologic-naïve group with graduate degrees (6), than in the biologic- experienced group (2). In the biologic-naïve group, 16 participants described their $\mathrm{CD}$ as moderate in severity, and five participants described their $\mathrm{CD}$ as severe, compared with 15 and 7, respectively, in the biologic-experienced group. The disease duration was slightly higher in the biologic-experienced group (range: 1-42 years; mean: 13.32 years) compared with the biologicnaïve group (range: $1-40$ years; mean: 10.50 years).

The participants reported few concurrent conditions; one participant reported psoriasis, and five participants reported rheumatoid arthritis. In addition to the drugs used to treat CD and related conditions, only one participant reported taking an antidepressant.

The greatest difference between the biologic naïve and biologic-experienced groups was in level of employment. In the biologic naïve group, three participants were 
Table 3 Focus-group participant demographics

\begin{tabular}{|c|c|c|}
\hline & $\begin{array}{l}\text { Biologic naïve } \\
n=21\end{array}$ & $\begin{array}{l}\text { Biologic experienced } \\
n=22\end{array}$ \\
\hline \multicolumn{3}{|l|}{ Participants } \\
\hline Recruited & 24 & 24 \\
\hline Video diaries & 21 & 23 \\
\hline Group discussions & 21 & 22 \\
\hline \multicolumn{3}{|l|}{ Disease severity } \\
\hline Moderate & 16 & 15 \\
\hline Severe & 5 & 7 \\
\hline \multicolumn{3}{|l|}{ Education level } \\
\hline High school & 3 & 2 \\
\hline Some college & 3 & 6 \\
\hline College graduate & 12 & 12 \\
\hline Graduate degree & 6 & 2 \\
\hline \multicolumn{3}{|l|}{ Employment } \\
\hline Unemployed & 3 & 11 \\
\hline (due to $C D$ ) & $(2)$ & $(10)$ \\
\hline Self-employed & 2 & I \\
\hline Part-time work & 5 & I \\
\hline (due to $C D$ ) & $(0)$ & (I) \\
\hline Full-time work & 11 & 9 \\
\hline \multicolumn{3}{|c|}{ Income (thousand US\$ per year) } \\
\hline$<25$ & 0 & 4 \\
\hline $25-50$ & 4 & 9 \\
\hline $50-75$ & 11 & 5 \\
\hline $75-150$ & 5 & I \\
\hline $150+$ & 1 & 3 \\
\hline \multicolumn{3}{|l|}{ Disease duration } \\
\hline Range & $\mathrm{I}-40$ years & $\mathrm{I}-42$ years \\
\hline Mean & 10.50 years & 13.32 years \\
\hline
\end{tabular}

Abbreviation: $C D$, Crohn's disease.

unemployed (two due to $\mathrm{CD}$, one of whom claimed a disability). In the biologic-experienced group, of the eleven unemployed participants, ten claimed their unemployment was due to $\mathrm{CD}$ and six of those considered themselves disabled. Also in this group, one participant claimed disability but was able to work part time. All subjects claiming disability reported either that "my doctor put me on disability" or that they received some kind of assistance.

\section{Knowledge and awareness of CD}

Participants were generally aware that $\mathrm{CD}$ was incurable; they had some understanding of the genetic nature of $\mathrm{CD}$, but less awareness of the underlying etiology and medical aspects of CD.

\section{Autoimmune nature of $C D$}

Most participants believed their immune systems were weakened or deficient, and consequently unable to fight off some bacterium or other agent of their CD. Others believed their body was rejecting something, such as food or vitamins. In general, participants had a sense that their body, as a whole, was generally weaker because of $\mathrm{CD}$ and incapable of fighting any foreign substance, such as viruses.

\section{General impact of CD}

Although participants' disease durations ranged from recently diagnosed to long-term $\mathrm{CD}$, there were striking similarities in their personal descriptions of $\mathrm{CD}$ and its impact on their lives. For example, many participants remarked that $\mathrm{CD}$ had changed who they were and that they had adapted at least one aspect of their life (Table 4). In general, both biologic and nonbiologic participants reported a sense of good health status, in that many reported being in remission or feeling good, despite continuing physical symptoms of CD. This perception of their current health status was often judged relative to their past health experiences; that is, they perceived good health if they were feeling better or had improved symptoms, compared with the past when their $\mathrm{CD}$ was more symptomatic.

For some, remission meant improvement of the most bothersome symptoms, such as intense pain, or regaining a certain level of quality of life; however, few participants equated remission with a complete return to a normal state, and none really expected to achieve a state of normalcy similar to the state preceding their diagnosis. Many participants used other patients with more severe $\mathrm{CD}$ as benchmarks for their own personal health; if another patient had more severe symptoms, then the participant felt that he/she was doing all right. Participants had lived with their symptoms for so long that they did not know what normal was; the new normal of life with $\mathrm{CD}$ had become a benchmark. As a result of group discussions, some participants realized that their health status might not be as good as they believed it to be or potentially could be.

\section{Relationship with health care provider}

Participants had highly variable relationships with their health care providers. Close, trusting relationships were achieved when participants were treated by the same provider for several years, and this relationship somewhat influenced medication choices. Many participants reported implicit trust in their provider, believed that their provider recommended the best course of therapy, and relied heavily on these recommendations. Participants also reported poor experiences with other providers before finding their current provider. Lack of rapport with the provider or the provider not being highly knowledgeable about $\mathrm{CD}$ were cited as reasons for poor experiences. Participants with stable disease generally had intermittent relationships with their treating provider, 
Table 4 Impact of CD on various aspects of life

\begin{tabular}{|c|c|c|c|}
\hline Topic & Patient quotations & Sex & Treatment \\
\hline \multirow[t]{6}{*}{ General impact of CD } & "I got divorced because of it." & Female & Biologic \\
\hline & "It's not only affected my life, it's affected other people." & Male & Biologic \\
\hline & "l'd never be in remission where I have as much energy as you do." & Female & Nonbiologic \\
\hline & "I don't even know what normal is. You live with it." & Male & Nonbiologic \\
\hline & "I have their support but I don't let them know - they have no clue how sick I get." & Female & Nonbiologic \\
\hline & "Basically, it's impacted all my life. It took me 10 years to get out of school." & Male & Biologic \\
\hline \multirow[t]{2}{*}{ Relationship with provider } & $\begin{array}{l}\text { "He is such a guru of CD. He knows what people go through. I don't tell him } \\
\text { things unless he asks me." }\end{array}$ & Female & Nonbiologic \\
\hline & $\begin{array}{l}\text { "I don't share much about my life with my doctor. I assume it's a part of CD; } \\
\text { unless it's a specific event he needs to know about, I don't bring it up." }\end{array}$ & Male & Nonbiologic \\
\hline \multirow[t]{4}{*}{ Psychological impact of CD } & $\begin{array}{l}\text { "My first reaction was anger. I was so upset because I'm too young and healthy to } \\
\text { have this disease. Why is this happening to me? And then, I got depressed and } \\
\text { I finally said, 'Fine. If I have to take a pill every day and deal with it, I have to.' I still } \\
\text { get angry if I still get flare-ups after having taken my meds, but it's a 'why me' thing. } \\
\text { Life's not fair." }\end{array}$ & Female & Nonbiologic \\
\hline & $\begin{array}{l}\text { "I've become withdrawn, I'm not the same person I used to be. I feel like l've been } \\
\text { a burden to everyone around me." }\end{array}$ & Male & Biologic \\
\hline & $\begin{array}{l}\text { "They look at me like l'm eating poorly and bringing it on myself. They say things } \\
\text { like 'Can't you change your diet?"” }\end{array}$ & Female & Nonbiologic \\
\hline & "I feel like people think it's a disease that I gave myself by what I ate or didn't eat." & Female & Nonbiologic \\
\hline \multirow[t]{3}{*}{ Social impact of CD } & "When I'm sick and I get stressed out, she's there to pick up all the pieces." & Male & Biologic \\
\hline & $\begin{array}{l}\text { "l've become withdrawn. l'll date once in a while, but l'm really too tired to } \\
\text { do anything." }\end{array}$ & Male & Biologic \\
\hline & $\begin{array}{l}\text { "I haven't even approached dating because of the perianal [fistula]. I think it's gross } \\
\text { and disgusting." }\end{array}$ & Female & Biologic \\
\hline \multirow[t]{2}{*}{ Impact of CD on activities } & "Sometimes I don't even go places because of the urgency." & Male & Nonbiologic \\
\hline & $\begin{array}{l}\text { "I can't play football, which I like. I could run up and down the field and be OK. } \\
\text { But now I can't do that as much as I would like to do." }\end{array}$ & Male & Biologic \\
\hline \multirow[t]{2}{*}{ Impact of CD on professional life } & “I'm stuck with this job, even though l'm underpaid because of the insurance." & Female & Biologic \\
\hline & $\begin{array}{l}\text { "[My boss }] \text { was giving me a list of things I had done wrong, and one of them was } \\
\text { that I would just disappear and not tell her where I was going. I literally had to } \\
\text { go to the bathroom ... it got too stressful. I just couldn't take it anymore." }\end{array}$ & Male & Biologic \\
\hline
\end{tabular}

Abbreviation: CD, Crohn's disease.

did not have close relationships with their providers, and tended to visit their providers less frequently.

Regardless of the quality of the relationship with their providers, most participants were not completely open regarding the extent to which $\mathrm{CD}$ impacted their life (Table 3). Men seemed more hesitant to share details about their quality of life. Participants assumed that their providers would know how CD impacts them, because they believed that much of the impact was common to the disease and that the providers would already be aware of relevant issues, since they were experts.

\section{Impact on various aspects of daily life}

\section{Physical impact}

Several predominant physical symptoms appeared to have the most impact on participants' quality of life (Table 5). Gastrointestinal pain and joint pain, which are common comorbidities of $\mathrm{CD}$, were considered the most severe symptoms and the ones most difficult to live with. The gastrointestinal symptoms of diarrhea and flatulence were considered the most bothersome and embarrassing, respectively.

\section{Impact on diet}

The most commonly stated impact was on diet, and participants typically changed their diet entirely, cut out certain foods, or avoided entire food groups during CD flares. Participants missed the days when they could eat anything; food was a reminder of their illness. Participants described periods of feeling healthy, in which they ate "forbidden" foods, only to find themselves with stomach pains the next day.

\section{Psychologic impact of CD}

Nearly all participants described CD as an embarrassing and silent disease, and these aspects had considerable psychologic impact. Embarrassing aspects of CD included frequent trips to the bathroom, fear of soiling themselves, and a frequent need to pass gas. Participants appeared highly self-conscious 
Table 5 Predominant CD-related physical symptoms

\begin{tabular}{|c|c|}
\hline Symptom & Characteristics \\
\hline $\begin{array}{l}\text { Intense gastrointestinal } \\
\text { pain }\end{array}$ & $\begin{array}{l}\text { - Intestinal cramping often debilitating, } \\
\text { with patients sometimes ending up in } \\
\text { the hospital }\end{array}$ \\
\hline Joint pain & $\begin{array}{l}\text { - Often considered most difficult symptom } \\
\text { to live with } \\
\text { - Includes difficulty getting out of bed in } \\
\text { the morning } \\
\text { - Everyday tasks exhausting at times } \\
\text { - Patients give up exercising, engage in } \\
\text { fewer activities with children and friends }\end{array}$ \\
\hline Fatigue & $\begin{array}{l}\text { Patients learn to live with the fatigue, } \\
\text { push through it, but often regret time } \\
\text { lost to sleeping }\end{array}$ \\
\hline $\begin{array}{l}\text { Diarrhea/frequency/ } \\
\text { urgency }\end{array}$ & $\begin{array}{l}\text { - Considered most bothersome aspect } \\
\text { of the disease } \\
\text { - Impact on patients varied; severely } \\
\text { debilitating for some } \\
\text { - Coping strategies help manage urgency }\end{array}$ \\
\hline Excessive gas & $\begin{array}{l}\text { - One of the more embarrassing aspects } \\
\text { of the disease }\end{array}$ \\
\hline
\end{tabular}

Abbreviation: CD, Crohn's disease.

and concerned about others' opinions about their disease, and they had developed coping strategies. Many avoided public restrooms or sought less-frequented restrooms in their office building. Some also waited to use the restroom until it was empty or prayed that nobody recognized their shoes. Women, in general, appeared more self-conscious than men did.

Patients do not always have outwardly visible signs of $\mathrm{CD}$, which leads to misperceptions of the disease's severity or degree of suffering. Some women put on weight in contradiction to the usual symptoms of the disease, furthering misperceptions about it. Participants felt that little was known about $\mathrm{CD}$, and that society as a whole did not talk about it. Lack of understanding and support furthers feelings of depression and loneliness. For example, a few participants reported that friends or family would point to their diet or lifestyle as reasons for the illness, that people did not believe that CD was a real illness, or that they thought it was an eating disorder (Table 4). Participants did not easily share information about their disease with those who were not close to them. Participants felt that even friends and family members often did not understand what CD patients were going through in dealing with CD. Conversely, participants pointed out that once they began talking about $\mathrm{CD}$, they realized there was a rather large number of people who either had CD or knew someone who had it. Despite a general lack of interest in support-group participation in this cohort, respondents eagerly sought and shared information with one another, both during the group discussion and after the moderator had left the room, suggesting that patients could benefit from more outreach/support groups.

\section{Social impact}

Participants described being more withdrawn and less social, avoiding social functions, or even changing their circle of friends. Several participants avoided meeting friends or colleagues for drinks because they were tired of making excuses about why they could not drink alcohol or have certain foods. One participant completely changed her social network because her activities and interests were altered owing to limitations imposed by CD. In addition, many participants declined invitations or left events early because of fatigue.

Participants who were single believed that they were unattractive and unappealing to potential romantic partners (Table 4). Some single women had given up on dating, particularly those with external fistulas. For example, a young woman envisioned her future self as an "old maid with a bunch of cats." Likewise, a young man was not sure whether he would get married out of his concern over burdening a future spouse with his disease. Participants currently in relationships described their partners as important sources of support and encouragement (Table 4). Some participants met their partners prior to $\mathrm{CD}$ diagnosis, whereas others met their partners afterward. CD often created tension in a relationship. For example, some women reported marital tension because of intimacy issues. Loss of sex drive because of cramping, pressure, pain, or generalized fatigue was reported. At least one man reported erectile dysfunction that required prescription medication.

Those with children, particularly women, were deeply saddened by the impact the disease had on their ability to care for their children. Reasons for this remorse included having to miss children's sporting events, not being able to take a toddler to the park as frequently as desired, and burdening the children when they had to care for a parent that was not feeling well. Some women reported that they would have children (or have more children) if they did not have CD, but were concerned about feeling ill during pregnancy or not being able to care for the child, owing to fatigue. Some participants said that they avoided telling their family when they were not feeling well, out of concern over becoming a burden to them. Participants with CD that was not wellcontrolled expressed concern about traveling long distances and their need for frequent bathroom breaks, which was cited as limiting their ability to visit family members who lived in other states. 


\section{Impact on activities and professional life}

Beyond social occasions, participants were unable to participate in activities and outings they once enjoyed (Table 4). These activities included travel and athletic activities. Participants with more severe CD reported cutting back on their work schedules, changing careers, or exiting the workforce entirely (Table 4).

Teachers were unable to leave their classes alone for bathroom breaks, and one woman could no longer travel to developing countries, as required for her job. Several participants noted that $\mathrm{CD}$ had impacted their choice of profession or that the need for health benefits prevented them from taking certain jobs or starting their own businesses. Some participants chose a desk job or one that allowed them the freedom, when needed, to go to the bathroom, to attend doctor/nurse-practitioner appointments, or to leave for urgent follow-up office appointments.

From a work perspective, many participants were initially reluctant to discuss their condition out of concern over the potential repercussions. Participants generally disclosed their condition to their employer after a certain period of time after gaining the trust and understanding of coworkers. Although most employers were understanding and accommodating, participants described stressful environments, especially in regard to using stalls in large bathrooms and to having difficulties meeting performance requirements; such circumstances eventually resulted in the need to go on disability or seek part-time employment. Some participants experienced involuntary loss of employment because of extended absences related to their disease.

\section{Coping mechanisms}

Participants adopted coping mechanisms to help them deal with the physical, emotional, or social aspects of $\mathrm{CD}$ (Table 6). Bowel movements (eg, diarrhea) were the symptom with the greatest need for coping strategies. Participants also developed coping strategies for diet, stress, fatigue, and choice of clothing (eg, for comfort and potential accidents). Participants did not seem to actively seek out other patients with CD for support (eg, via support groups or online communities).

\section{Differential impact on men and women}

Some sex-based differences in the impact of $\mathrm{CD}$ were noted, including that women tended to feel a stronger emotional burden from the disease, whereas the physical impact of the disease tended to be a greater burden for men. Women often described the strain of $\mathrm{CD}$ on relationships with children and
Table 6 General coping strategies

\begin{tabular}{ll}
\hline Issue & Modifications made \\
\hline Diet & - Avoiding specific foods: spicy food, sugar, \\
& dairy, popcorn, rich food \\
& - Avoiding certain beverages: beer/alcohol, \\
& carbonated drinks \\
& - Skipping meals \\
Bathroom habits: & - Mapping out locations of all bathrooms \\
urgency and & - Carrying toilet seat covers/room sprays \\
frequency & - Planning meals around outings and activities \\
& - Taking antidiarrheal medication, depending \\
& - on activities \\
Fatigue & - Carrying NACC "Can't Wait" card \\
Stress & - Sleeping more \\
& - Exercising (although fatigue somewhat limits \\
& - it for some) \\
& - Doing mental exercises/channeling \\
Clothing & - Wiffusing stress from the disease with humor \\
& - Wearing baggy/comfortable clothing \\
& - Carrying a change of clothes
\end{tabular}

Note: The NACC is a UK organization (http://www.nacc.org.uk/content/home.asp). Abbreviation: NACC, National Association for Crohn's and Colitis.

spouses and the need for constant support; however, women indicated more openness than did men in seeking support and discussing symptoms with close friends, family, or their health care provider. Men resented the loss of involvement or ability to participate in physical activities because of the fatigue, pain, or bathroom needs associated with $\mathrm{CD}$. Both men and women were impacted by self-esteem issues directly related to the embarrassing symptoms of $\mathrm{CD}$.

\section{Current medication}

Triggers for and barriers to biologic therapy

Triggers for initiating biologic therapy included a major episode involving hospitalization or surgery, the lack or loss of the efficacy of previous treatments, the desire to avoid surgery despite the worsening of the disease while receiving other therapies, and the adverse effects of other treatments. Focus-group discussions also revealed that biologic therapy seemed to be triggered by proactive patients who demanded more effective treatment or by proactive providers who believed that their patients should be treated with biologic therapy.

Participants receiving biologic therapy tended to selfreport better adherence, compared with participants receiving conventional nonbiologic oral medications. In addition, participants in the biologic cohort were aware that biologic agents acted by weakening the immune system. Safety concerns with biologic therapy, in particular the potentially 
greater risk of developing cancer, were a barrier to initiating biologic therapy for some, but the desire for better symptom control outweighed the safety concerns of those receiving biologic therapy. Some biologic-naïve participants whose conventional therapies were relieving their most bothersome symptoms, though not all of them, were reluctant to initiate biologic therapy, even though additional benefits, such as better symptom control and the return of normal functionality, might be achieved.

\section{Satisfaction and adherence}

Participants consistently reported at least some level of satisfaction with their current medication regimens and believed their medications were working for them, because they felt better than in the past, regardless of the current severity of their symptoms. Many of the participants did not proactively ask their providers about new treatment options or regimens, because they viewed their current state of health and symptom control as a "new normal" and assumed that their providers would tell them if a better treatment option were available. Participants receiving biologic therapy appeared to be physically and emotionally better than those not receiving biologic therapy; they reported a high degree of satisfaction with their therapy, more energy, a return to a functional level of activity, and more normal diet and eating patterns. Participants receiving conventional therapy generally reported less satisfaction with their current therapy, compared with participants receiving biologic therapy. Overall, the biologic-experienced groups appeared somewhat more informed and proactive about their treatment choices than did biologic-naïve groups.

Participants' satisfaction with treatment efficacy was reflected in the high patient-reported adherence to biologics. Adherence to biologic therapy seemed to be related to the desire to sustain relief from the most severe or bothersome symptoms and to not wanting to run the risk of these symptoms returning. In contrast, participants taking daily oral medications often expressed more concern about risks associated with chronic therapy. Moreover, these participants were prone to skipping doses, forgetting to take their medication, or discontinuing their medication when their symptoms improved. Participants receiving conventional therapy invariably reported less satisfaction with their current therapy than did participants receiving biologic therapy. Overall, the biologic-experienced groups appeared somewhat more informed and proactive about their treatment choices than were biologic-naïve groups.

\section{Outlook for the future}

Regardless of how well their symptoms were being managed, participants questioned their future health and relationships; the unpredictability of the disease made many participants wonder how they would feel the next day. Participants who had severe symptoms in the past constantly feared the recurrence of a flare-up, and participants had concerns about needing surgery, in particular a stoma or ostomy. The benefits of short-term relief of symptoms seemed to outweigh fear of the adverse effects of medications; nevertheless, participants were concerned about developing other illnesses, such as cancer, as a direct result of chronic medication use.

\section{Discussion Study limitations}

The limitations of this study include the relatively small sample size and the qualitative nature of the research. One bias that could have been introduced by the selection process was that respondents in this type of research tend to be highly proactive and articulate, because participation is self-selected. In addition, because of the nature of the disease, some respondents were not in a physical condition that allowed them to participate at a central location. Ideally, multimodal methods of recruiting participants would ensure good representation of the population with $\mathrm{CD}$. Because the study focused on CD in a relatively homogeneous sample of patients who were recruited from US cities in which IBD referral centers were located, the generalizability to patients with ulcerative colitis or other geographic locations may be limited. Finally, this research did not attempt to describe the specific involvement of nurses, the relationship between the nurse practitioner as the provider and the patient, or that relationship's impact on the patients' decision making regarding choice of medications, satisfaction with care, medication adherence, and knowledge about their CD and treatment options.

\section{Impact of CD}

Patients with chronic diseases face many challenges when integrating illnesses into their lives and achieving an acceptable quality of life; these challenges include psychosocial, physical, and work-related aspects. ${ }^{23}$ We found that many patients with $\mathrm{CD}$ accepted a new normal state of being because they did not have expectations that treatment could be effective enough to sustain true remission or restore normal function, activity, and quality of life. Early research on the concerns of patients with IBD identified loss of energy, loss of control, poor body image, isolation and fear, being 
a burden, feeling dirty, and lack of information from health care providers as common concerns. ${ }^{24} \mathrm{~A}$ more recent study of worries and concerns in a cohort of 447 Swedish patients with CD identified ostomy, energy level, and bowel control as the top concerns, and disease-related complications and daily-life achievements were of more concern to patients than were intimacy or stigmatization. ${ }^{25}$ We identified similar concerns in our study, although participants' relationships with health care providers seem to have improved, perhaps because of increased knowledge regarding the etiology of CD and newer, more effective treatments, such as biologic therapies. In addition, participants in our study described significant feelings of stigmatization attributable to $\mathrm{CD}$ : perceived $\mathrm{CD}$-related stigma has been shown to be associated with poorer outcomes and decreased medication adherence. ${ }^{26}$

\section{Patient-provider relationship}

Numerous studies and reviews of patient perspectives in CD conducted in the United States and other countries have yielded largely similar results, concluding that patient education and involvement in the decision-making processes for the management of CD are critical and important to patients. ${ }^{4,5,19,22,27-29}$ In a study of more than 1000 Dutch patients with IBD, nearly all the patients thought it was important to be actively involved in treatment decisions, and 50\% indicated that treatment could be improved with a close and equitable relationship with their physician, particularly those with a disease duration of at least 8 years. ${ }^{27}$ Results from a European study of over 5000 patients were qualitatively similar to our findings. ${ }^{5}$ If given a choice, $86 \%$ of patients reported that they would try a new type of therapy before undergoing surgery. Approximately half of the patients said that their doctor did not inquire about the impact of the disease on their quality of life.

\section{Acceptance of biologic therapy}

We found that participants who were reluctant to share symptoms and quality-of-life issues were less likely to receive biologic therapy, despite being eligible for it. Likewise, willingness to accept the potential risks of biologic therapy may differ between patients and gastroenterologists, particularly if the provider is unaware of how debilitating the disease is on an individual patient's day-to-day activities and if the patient is unaware that they might be eligible to receive biologic therapy. ${ }^{30,31}$ Siegel $^{20}$ described the process of deciding to initiate biologic therapy as being preference sensitive and involving risk perceptions that were influenced by factors such as expectations of efficacy, risk aversions, severity of illness, tolerance of symptoms, and knowledge about available treatments. Participants in our study had a perception that biologics should be reserved for use as a last resort, and this was identified as a barrier to initiating biologic therapy.

Increased severity of symptoms was typically the trigger for biologic treatment in this study. Similarly, Johnson et al ${ }^{30}$ reported that daily symptom severity was the most important factor in patient preferences regarding treatment for $\mathrm{CD}$, and that patients were willing to accept certain known risks of biologic therapy because of their greater efficacy. Patients with milder symptoms were more willing to accept risks to avoid more serious symptoms than were patients who had more severe symptoms; this finding is consistent with our findings that patients with CD tolerate unresolved symptoms and develop coping mechanisms rather than seek more effective therapy. There is also evidence to suggest that gastroenterologists are less tolerant than patients are of serious risks incurred by seeking improvements, from moderate symptoms to remission, and that the risk tolerance varies depending on the patient profile. ${ }^{31}$ The importance of ensuring that patients understand the risk-benefit profile of biologic therapy was highlighted in two studies that found that patients with IBD likely overestimated the remission rates of infliximab and underestimated the risks. ${ }^{32,33}$ Consequently, patients may make treatment decisions based on inaccurate perceptions. Although respondents in our study mentioned the safety risks of biologics and the negative safety or adverse effects of steroid therapy during the group discussions, their awareness of the safety risks of immunosuppressants and other therapies was minimal.

\section{Future implications and role of nurses}

Future implications from this research include the need to improve provider-patient relationships to facilitate shared decision making, raise patients' treatment expectations to empower patients to be more proactive about their treatment, and raise awareness of patient support networks. Although our research did not explicitly address the role of nurses and nurse practitioners, studies of IBD and other chronic illnesses have shown that nurse practitioners have a pivotal role in empowering patients to be active participants in their care and ensuring that patients receive quality care. ${ }^{21,22,34-40}$

Similar to our findings, Cooper et $\mathrm{al}^{34}$ reported that a lack of knowledge about IBD on the part of health care staff, employers, and society in general was a substantial barrier to patients' personal control and self-management; however, nurses prepared to discuss the specifics of the 
discrepancies and uncertainties of living with IBD could greatly enhance patient care. Westwood and Travis ${ }^{22}$ suggested that including an IBD nurse specialist on a multidisciplinary team of health care providers was an important factor in patient care because patients might be more comfortable discussing their concerns with the nurse specialist, who could then become an advocate for the patient. A UK study of the benefits, from the stakeholders' perspective, of IBD nurse specialists found that nurses could bridge the communication gap that sometimes existed between the physician and the patient. ${ }^{35}$ Likewise, Nightingale et $\mathrm{al}^{21}$ reported that patients' satisfaction with their care improved in the year after IBD nurse specialists became involved, particularly in the areas of disease-related information, avoiding illness, and maintaining health.

Evidence also suggests that IBD nurse specialists can improve outcomes. Specifically in the UK, the IBD nurse specialist has been shown to effectively develop a protocol-led service for immunomodulators, ${ }^{41}$ implement a self-management program, ${ }^{42}$ implement a program for the administration of methotrexate, ${ }^{43}$ reduce visits and in-patient lengths of stay, ${ }^{21}$ improve treatment adherence, ${ }^{44}$ and improve access to care and services. ${ }^{45-47}$ Specifically with regard to biologic therapy, nurse practitioners have been shown to have an important role in optimizing outcomes through patient education and advocacy in patients with rheumatoid arthritis, which is another chronic condition for which biologic therapies are approved. ${ }^{48}$

\section{Conclusion}

Participants described the dramatic impact of CD on their lives, including fear, embarrassment, and the withholding of information from their providers. They also described how these factors impacted their treatment decisions. Accepting that relief of only the most bothersome symptoms was adequate, many participants accepted a new state of normalcy in living with CD instead of expecting more effective treatment that could provide sustained remission. Their awareness of biologic therapies was mixed, but participants receiving biologic therapy generally seemed to be more satisfied with their treatment and more likely to adhere to treatment regimens, suggesting a need for more patient education and more collaborative relationships between patients and providers.

\section{Acknowledgments}

Medical writing services were provided by Eileen $M$ Burkhart-Hartman, PhD, of Abbott Laboratories; Cathryn M
Carter, MS, of Arbor Communications; and Elaine Hanna, MA. This support was funded by Abbott Laboratories. The authors would like to thank the patients for their participation in this research.

\section{Author contributions}

$\mathrm{BN}$ provided intellectual content for and critical review of the manuscript. RT secured funding, conceptualized the study and analyzed the data, and provided intellectual content for and critical review of the manuscript. KGL analyzed the data and provided intellectual content for and critical review of the manuscript. SDB provided intellectual content for and critical review of the manuscript.

\section{Disclosure}

Beth-Ann Norton is a consultant for UCB and Abbott Laboratories. Rosemarie Thomas is an employee of Abbott Laboratories and owns stock. Sharon Dudley-Brown is a consultant for Shire, UCB, and Salix Pharmaceuticals. Kathleen G Lomax is a former employee of Abbott Laboratories. Abbott was the financial sponsor of this study. This research was conducted by $\mathrm{M} / \mathrm{A} / \mathrm{R} / \mathrm{C}$ Research under contract with Abbott.

\section{References}

1. Kappelman MD, Rifas-Shiman SL, Kleinman K, et al. The prevalence and geographic distribution of Crohn's disease and ulcerative colitis in the United States. Clin Gastroenterol Hepatol. 2007;5(12): $1424-1429$.

2. Loftus EV Jr, Schoenfeld P, Sandborn WJ. The epidemiology and natural history of Crohn's disease in population-based patient cohorts from North America: a systematic review. Aliment Pharmacol Ther. 2002;16(1):51-60.

3. Loftus CG, Loftus EV Jr, Harmsen WS, et al. Update on the incidence and prevalence of Crohn's disease and ulcerative colitis in Olmsted County, Minnesota, 1940-2000. Inflamm Bowel Dis. 2007;13(3): 254-261.

4. Pieper C, Haag S, Gesenhues S, Holtmann G, Gerken G, Jockel KH. Guideline adherence and patient satisfaction in the treatment of inflammatory bowel disorders - an evaluation study. BMC Health Serv Res. 2009;9:17.

5. Ghosh S, Mitchell R. Impact of inflammatory bowel disease on quality of life: Results of the European Federation of Crohn's and Ulcerative Colitis Associations (EFCCA) patient survey. J Crohns Colitis. 2007;1(1):10-20.

6. Dignass A, Van Assche G, Lindsay JO, et al. The second European evidence-based consensus on the diagnosis and management of Crohn's disease: current management. J Crohns Colitis. 2010;4(1):28-62.

7. Lichtenstein GR, Hanauer SB, Sandborn WJ. Management of Crohn's disease in adults [quiz 464 and 484]. Am J Gastroenterol. 2009;104(2):465-483.

8. Oldenburg B, Hommes D. Biological therapies in inflammatory bowel disease: top-down or bottom-up? Curr Opin Gastroenterol. 2007;23(4):395-399.

9. Hanauer SB. Clinical perspectives in Crohn's disease. Turning traditional treatment strategies on their heads: current evidence for "stepup" versus "top-down." Rev Gastroenterol Disord. 2007;7(Suppl 2): S17-S22. 
10. Colombel JF, Sandborn WJ, Reinisch W, et al. Infliximab, azathioprine, or combination therapy for Crohn's disease. New Engl J Med. 2010;362(15):1383-1395.

11. Hanauer SB, Sandborn WJ, Rutgeerts P, et al. Human anti-tumor necrosis factor monoclonal antibody (adalimumab) in Crohn's disease: the CLASSIC-I trial. Gastroenterology. 2006;130(2):323-333.

12. Hanauer SB, Feagan BG, Lichtenstein GR, et al. Maintenance infliximab for Crohn's disease: the ACCENT I randomised trial. Lancet. 2002;359(9317):1541-1549.

13. Colombel JF, Sandborn WJ, Rutgeerts P, et al. Adalimumab for maintenance of clinical response and remission in patients with Crohn's disease: the CHARM trial. Gastroenterology. 2007;132(1):52-65.

14. Targan SR, Hanauer SB, van Deventer SJH, et al. A short-term study of chimeric monoclonal antibody cA2 to tumor necrosis factor-alpha for Crohn's disease. Crohn's Disease cA2 Study Group. New Engl J Med. 1997;337(15):1029-1035.

15. Sandborn WJ, Rutgeerts P, Enns R, et al. Adalimumab induction therapy for Crohn disease previously treated with infliximab: a randomized trial. Ann Intern Med. 2007;146(12):829-838.

16. Sandborn WJ, Feagan BG, Stoinov S, et al. Certolizumab pegol for the treatment of Crohn's disease. New Engl J Med. 2007;357(3): 228-238.

17. Schreiber S, Khaliq-Kareemi M, Lawrance IC, et al. Maintenance therapy with certolizumab pegol for Crohn's disease. New Engl J Med. 2007;357(3):239-250.

18. Irving EJ. Review article: patients' fears and unmet needs in inflammatory bowel disease. Aliment Pharmacol Ther. 2004; 20(Suppl 4):S54-S59.

19. Mitchell R, Kremer A, Westwood N, Younge L, Ghosh S. Talking about life and IBD: a paradigm for improving patient-physician communication. J Crohns Colitis. 2009;3(1):1-3.

20. Siegel CA. Making therapeutic decisions in inflammatory bowel disease: the role of patients. Curr Opin Gastroenterol. 2009;25(4): 334-338.

21. Nightingale AJ, Middleton W, Middleton SJ, Hunter JO. Evaluation of the effectiveness of a specialist nurse in the management of inflammatory bowel disease (IBD). Eur J Gastroenterol Hepatol. 2000;12(9):967-973.

22. Westwood N, Travis SP. Review article: what do patients with inflammatory bowel disease want for their clinical management? Aliment Pharmacol Ther. 2008;27(Suppl 1):S1-S8.

23. Whittemore R, Dixon J. Chronic illness: the process of integration. J Clin Nurs. 2008;17(7B):177-187.

24. Casati J, Toner BB, de Rooy EC, Drossman DA, Maunder RG. Concerns of patients with inflammatory bowel disease: a review of emerging themes. Dig Dis Sci. 2000;45(1):26-31.

25. Stjernman H, Tysk C, Almer S, Strom M, Hjortswang H. Worries and concerns in a large unselected cohort of patients with Crohn's disease. Scand J Gastroenterol. 2010;45(6):696-706.

26. Taft TH, Keefer L, Leonhard C, Nealon-Woods M. Impact of perceived stigma on inflammatory bowel disease patient outcomes. Inflamm Bowel Dis. 2009;15(8):1224-1232.

27. Baars JE, Markus T, Kuipers EJ, van der Woude CJ. Patients' preferences regarding shared decision-making in the treatment of inflammatory bowel disease: results from a patient-empowerment study. Digestion. 2010;81(2):113-119.

28. Magro F, Portela F, Lago P, et al. Inflammatory bowel disease: a patient's and caregiver's perspective. Dig Dis Sci. 2009;54(12): 2671-2679.

29. Zutshi M, Hull TL, Hammel J. Crohn's disease: a patient's perspective. Int J Colorectal Dis. 2007;22(12):1437-1444.
30. Johnson FR, Ozdemir S, Mansfield C, et al. Crohn's disease patients' risk-benefit preferences: serious adverse event risks versus treatment efficacy. Gastroenterology. 2007;133(3):769-779.

31. Johnson FR, Hauber B, Ozdemir S, Siegel CA, Hass S, Sands BE. Are gastroenterologists less tolerant of treatment risks than patients? Benefit-risk preferences in Crohn's disease management. JManag Care Pharm. 2010;16(8):616-628.

32. Baars JE, Siegel CA, Kuipers EJ, van der Woude CJ. Patient's perspectives important for early anti-tumor necrosis factor treatment in inflammatory bowel disease. Digestion. 2009;79(1):30-35.

33. Siegel CA, Levy LC, Mackenzie TA, Sands BE. Patient perceptions of the risks and benefits of infliximab for the treatment of inflammatory bowel disease. Inflamm Bowel Dis. 2008;14(1):1-6.

34. Cooper JM, Collier J, James V, Hawkey CJ. Beliefs about personal control and self-management in 30-40 year olds living with Inflammatory Bowel Disease: a qualitative study. Int J Nurs Stud. 2010;47(12):1500-1509.

35. Belling R, Woods L, McLaren S. Stakeholder perceptions of specialist Inflammatory Bowel Disease nurses' role and personal attributes. Int J Nurs Pract. 2008;14(1):67-73.

36. Aigner MJ, Drew S, Phipps J. A comparative study of nursing home resident outcomes between care provided by nurse practitioners/ physicians versus physicians only. J Am Med Dir Assoc. 2004;5(1): 16-23.

37. Lambing AY, Adams DL, Fox DH, Divine G. Nurse practitioners' and physicians' care activities and clinical outcomes with an inpatient geriatric population. J Am Acad Nurse Pract. 2004;16(8):343-352.

38. Hekkink CF, Wigersma L, Yzermans CJ, Bindels PJ. HIV nursing consultants: patients' preferences and experiences about the quality of care. J Clin Nurs. 2005;14(3):327-333.

39. Wilson IB, Landon BE, Hirschhorn LR, et al. Quality of HIV care provided by nurse practitioners, physician assistants, and physicians. Ann Intern Med. 2005;143(10):729-736.

40. Ohman-Strickland PA, Orzano AJ, Hudson SV, et al. Quality of diabetes care in family medicine practices: influence of nurse-practitioners and physician's assistants. Ann Fam Med. 2008;6(1):14-22.

41. Holbrook K. A triangulation study of the clinician and patient experiences of the use of the immunosuppressant drugs azathioprine and 6-mercaptopurine for the management of inflammatory bowel disease. J Clin Nurs. 2007;16(8):1427-1434.

42. Stansfield C, Robinson A. Implementation of an IBD nurse-led self-management programme. Gastrointestinal Nursing. 2008;6(3): 12-18.

43. Garrick V, Atwal P, Barclay AR, McGrogan P, Russell RK. Successful implementation of a nurse-led teaching programme to independently administer subcutaneous methotrexate in the community setting to children with Crohn's disease. Aliment Pharmacol Ther. 2009;29(1):90-96.

44. Schreiber S, Hamling J, Wedel S, Nikolaus SN, Buhr HJ, Raedler A. Efficacy of patient education in chronic inflammatory bowel disease in a prospective controlled multicentre trial. Gastroenterology. 1999; 116:A815

45. Pearson C. Establishing an inflammatory bowel disease service. Nurs Times. 2006;102(23):28-29.

46. Miller L, Caton S, Lynch D. Telephone clinic improves quality of follow-up care for chronic bowel disease. Nurs Times. 2002;98(31): 36-38.

47. Younge L, Norton C. Contribution of specialist nurses in managing patients with IBD. Br J Nurs. 2007;16(4):208-212.

48. Coughlin M. Improving patient outlook in rheumatoid arthritis: experience with abatacept. J Am Acad Nurse Pract. 2008;20(10):486-495. 


\section{Publish your work in this journal}

Patient Preference and Adherence is an international, peer-reviewed, open access journal focusing on the growing importance of patient preference and adherence throughout the therapeutic continuum. Patient satisfaction, acceptability, quality of life, compliance, persistence and their role in developing new therapeutic modalities and compounds to

optimize clinical outcomes for existing disease states are major areas of interest. This journal has been accepted for indexing on PubMed Central. The manuscript management system is completely online and includes a very quick and fair peer-review system. Visit http://www.dovepress.com/ testimonials.php to read real quotes from published authors.

Submit your manuscript here: http://www.dovepress.com/patient-preference-and-adherence-journal 